\title{
O renascer de um debate: administração, poder e política colonial
}

\author{
Antonio Filipe Pereira Caetano
}

SOUZA, Laura de Mello e. O sol e a sombra: política e administração na América Portuguesa do século XVIII. São Paulo: Companhia das Letras, 2007.

Durante a década de 70, a historiografia sobre a América portuguesa sofreria um duplo abalo. Internamente, as obras de Ciro Flamarion Cardoso e Jacob Gorender questionavam a máxima inaugurada e perpetuada nos anos anteriores que enrijecia a relação entre Portugal e suas conquistas americanas, bem como apontava a dependência, através do "pacto colonial", destas últimas em detrimento da primeira. $\mathrm{Na}$ prática, estes autores punham em xeque a teoria do "sentido da colonização" de Caio Prado Júnior, mas respaldada por Celso Furtado e Fernando Novais. Preocupados em entender a dinâmica interna, Cardoso e Gorender tentavam demonstrar que havia uma "vida própria e autônoma" nos confins da América, e que as necessidades da coroa portuguesa não impediam a proliferação de outros modos de uso do negro e de atividades agrícolas.

Externamente, o complexo colonial lusitano e as estruturas do Antigo Regime também foram questionadas com os trabalhos de Charles R. Boxer, A.J. Russell-Wood, Francisco Bethencourt, Antonio Manuel Hespanha e outros. De um lado, Portugal passava a não ser visto mais isoladamente e sim inserido em um complexo ultramarino, marcado por uma teia de relações sociais que o dotavam de amplos tentáculos imperiais que precisavam ser harmonizados; do outro, sua estrutura política absolutista foi relativizada, demonstrando a existência de um corpo administrativo auxiliar e de um poder corporativo e polissinodal.

Os reflexos desses novos olhares, novas propostas e descobertas empurraram a historiografia colonial a tentar enxergar peculiaridades, especificidades e individualidades nas décadas seguintes. João Fragoso, Maria Fernanda Baptista Bicalho, Júnia Furtado, Maria de Fátima Gouvêa, Stuart Schwartz, só para ficar em alguns casos, aprofundaram as pistas deixadas pelos historiadores dos anos 70 e descortinaram uma nova América portuguesa: com uma economia multifacetada, uma base política marcada pela negociação, com uma sociedade ampla, complexa e desenhada por características lusitanas adaptadas. Todavia, quando ninguém mais esperava pensar na relação centralizadora entre "centro" e "periferia" e/ou "colônia" e "metrópole", eis que surge entre as nuvens $O$ Sol e a Sombra de Laura de Mello e Souza, como uma espécie de retorno aos ideais inaugurados por Caio Prado Júnior.

Usando a metáfora do jesuíta Antonio Vieira da associação do Rei ao sole dos administradores régios à sombra, a autora tem por intenção demarcar a posição de mando na América portuguesa, reforçando seus laços de autoridade com o reino. Por conta disso, a mesma se enfronha na delicada manutenção da administração portuguesa em terras americanas, local onde o monarca estaria constantemente ausente. Mas, se a princípio podemos imaginar que a distância traria inúmeras conjecturas problemáticas, foi justamente o inverso que se desenhou: súditos suplicando pela autoridade e soberania do Sol. Assim, a intenção de Souza é revelar como funcionava essa estrutura administrativa tão peculiar, utilizando como corte temporal o século XVIII e como corte geográfico a "opulenta” Minas Gerais.

Interessada em fazer uma evidente separação entre teoria e prática, a autora dividiu o trabalho em duas partes: Enquadramentos e Individuos. Tal objetivo demonstra uma intenção de tentar configurar um cenário teórico, contextual e imperial para, em seguida, perceber como aquelas se comportam no momento de análise daqueles homens realmente envolvidos no cotidiano da prática colonial americana.

Em Enquadramentos, usando o método do funil, Souza inicia sua discussão apresentando o debate historiográfico sobre a questão administrativa colonial. Sem dúvida alguma é a parte mais ousada e crítica da obra, já que, neste exato momento, o resgate do binômio "colônia versus metrópole" será feito buscando uma releitura bem particular. 
Desenterrando obras sobre a política colonial, a autora chega ao debate historiográfico recente no qual vê a noção de império e a adaptação do $A n$ tigo Regime nos trópicos como algo problemático e feito de forma não muito cuidadosa pelos contemporâneos. Além disso, a relativização do conceito de absolutismo para o caso português e sua imediata associação com seus domínios ultramarinos, deixaria escapar, em seu entendimento, um elemento essencial, a força motriz da relação reino e conquista durante a época moderna: a questão escravista. Logo, para Souza, pensar a administração colonial não pode deixar de lado o quão a escravidão (ameríndia ou africana) determinava as relações sociais, as necessidades econômicas e o quanto desembocava no reforço da força política.

Disto isto, a autora atesta sua principal tese, na qual não consegue perceber uma completa autonomia e/ou liberdade dos grupos sociais americanos frente à coroa portuguesa! Para ela, a necessidade de escravos impedia que as relaçõos fluíssem de maneira natural, até porque a aquisição de negros manchava a imagem da nobreza local, a distinguindo, substancialmente, daquela existente no reino. Para isso, a corrida desenfreada por títulos, honras, mercês e benesses se configuraria como uma alternativa viável para remediar a situação. E, exatamente por conta da dependência da concessão destes benefícios pelo monarca português, os grupos políticos sociais não possuíam liberdades frente ao Sol. A dependência era crônica, endêmica e se agrava ao longo dos anos. Neste caso, reforça-se a tendência centralizadora de centro português como referencial para as decisões sobre o mundo Atlântico.

Em um segundo momento, Souza nos apresenta a conjuntura política do século XVIII, tanto europeia, como paulista e mineira. Nesse momento, repete algumas ideias por ela já apresentada em trabalhos anteriores, como em Desclassificados do Ouro, onde o mundo mineiro seria marcado pela contradição entre a pobreza e a riqueza, desenvolvendo uma sociedade competitiva, opulenta e miserável. Contribuição interessante é a constatação do olhar que a coroa portuguesa tinha sobre suas conquistas americanas, que não se dava de forma total e sim fragmentada, de forma que cada localidade possuía uma função e um papel na tessitura imperial. Todavia, para Souza, este acabou se configurando co- mo um elemento negativo, pois acirrou os "localismos" e a falta de "unidade territorial".

Construindo o passado mineiro, a parada em São Paulo foi quase que obrigatória. Mas nesse caso, o ideal era a percepção dos elementos que permaneciam intactos após a Guerra dos Emboabas, episódio que culminou na separação física das duas localidades. Logo, a construção da imagem negativa dos paulistas como selvagens, bárbaros e rústicos se transformou em um recurso viável para legitimar a construção de uma redoma de vidro régia sobre a capitania de Minas Gerais. Afastadas as "pedras do sapato", o grande desafio era a construção de uma sociedade onde o controle deveria ser o principal tom. No entanto, para Souza, o que se viu emergir nas zonas auríferas foi uma sociedade "incômoda e improvisada”, com indivíduos oriundos de diversos cantos da América portuguesa e que, mais das vezes, carregavam consigo o estatuto e os modus vivendi das zonas açucareiras e queriam utilizá-lo em meio a uma sociedade em construção. Como resultado, um curto circuito, um caos!

Uma novidade fazia parte das características dessa nobreza das minas: a sua maior aproximação com o governo português, devido à sua distância. Todavia, a marca mameluca e uma proliferação de homens que se arrogavam nobres dotavam de um campo constante de disputa pelas honras do rei. Devido a estas marcas, a zona aurífera assistirá a emergência de uma sociedade que ela chama de "aluvial", ou seja, perecível, rotatória e volátil como o ouro. Por mais contraditório que seja, a sedimentação desses grupos só se dará com a crise dos metais, em fins do século XVIII, onde a mesma terá que buscar os meios agrícolas como elementos sustentáveis e transitórios para uma nova sociedade. Assim, evidentemente, a sociedade mineira, por possuir tais contornos, exigirá administradores com perfil firme, conciliador, fiéis escudeiros das determinações régias.

Neste ponto, Souza entra em Individuos, segunda parte do trabalho e onde o Sol cede lugar às suas Sombras. Os escolhidos para tal análise foram Dom Pedro de Almeida, o conde de Assumar (17171721); Sebastião da Veiga Cabral; Rodrigo César de Menezes ; Luis Diogo Lobo da Silva (1763-1968); Dom Antonio de Noronha (1775-1780); e Dom José Tomás de Menezes. Homens que administra- 
ram politicamente as Minas Gerais, ou que tiveram alguma relação por governar regiōes próximas, como São Paulo e a Colônia de Sacramento. A ideia era a confecção de um "raio x" da administração mineira, não perdendo de vista que a construção das linhas visava demonstrar a relação entre reino e as Minas, bem como demonstrar as Sombras auríferas como reprodutoras do embate político inaugurado no conflito do início do século XVIII que deu origem à região, sendo conclamadas para facilitar a concessão de títulos pelo Sol lusitano.

O Conde de Assumar teria uma imagem controvertida, principalmente por conta da ação sobre a Revolta de Felipe dos Santos, que o dotou de um perfil cruel, boçal e sanguinário, mas ao mesmo tempo culto, como um sagaz crítico do mundo ultramarino. Sebastiāo Cabral também vai ser marcado por características militares, mas teve dificuldades de alçar postos mais altos na estrutura administrativa portuguesa devido a seu sangue mestiço. Talvez por isso conseguia uma dupla personalidade, como homem mercantil e régio. Rodrigo César de Menezes, o mais multifacetado apontado por Souza, misturava características como tirania, hipocrisia, franqueza, rigidez, deslealdade e prudência; reflexo da disputa interna que a capitania vivia naquela altura, foi o único que consolidou o poder através da perpetuação de sua família na administração. Luis Diogo Lobo da Silva seria o espelho das ações pombalinas que já se faziam presentes na política colonial, angariando para si funções delicadas como a expulsão dos missionários e a aplicação da derrama. Dom Antonio de Noronha tinha um perfil mais flexível do que o de todos aqueles que passaram pelas Minas, mas foi um inimigo assumido do Tribunal do Santo Ofício; segundo Souza, sua gestão é exemplar na demonstração da maneira como a elite buscava mecanismos de perpetuação no poder. E Dom José Tomás de Menezes simboliza um império em crise e uma administração que pendulava entre a vida nos Trópicos e a ânsia de voltar para o reino.

$\mathrm{O}$ elemento em comum a todos estes homens era a alta circularidade nas administraçóes das conquistas ultramarinas. Grande parte destas sombras já havia adquirido experiência política em outras localidades lusas espalhadas pelo império, e o momento em que chegavam à região mineira representaria o ápice da escalada social. Com uma larga experiência militar, o critério da pureza do sangue não foi muito seguido para a capitania de Minas Gerais o interesse era um poder intenso, forte e que apaziguasse as inúmeras resistências dos súditos que lá viviam. O singular no trabalho da autora é demonstrar que os indivíduos, apesar de terem a função de sombra, o cotidiano local o empurram também para a condição de colonos, possibilitando o uso e abuso da máquina administrativa para conseguir benesses para si e para os seus. O resultado desta sobreposição de imagens pode ser averiguado nas inúmeras revoltas que a região mineira viu eclodir.

Por fim, Souza revela que teve a intenção de fazer um trabalho de micro-história quando analisou as trajetórias destes administradores, mesmo sabendo dos riscos, dificuldades e críticas que tal metodologia traz ao historiador no momento de seu uso. Talvez, esse tenha sido o recurso usado para reforçar a ideia da relação entre "colônia" e "metrópole", cotejadas como mundos distintos, porém complementares e interligados pela distribuição das mercês pela coroa portuguesa. No entanto, o reforço dessa hipótese torna-se contraditório exatamente no momento em que avalia a trajetória dos indivíduos, pois a autora demonstra que a disputa política está inserida em meio ao mundo administrativo, onde tais administradores/sombras faziam parte de jogo. Entretanto, para além da Sombra e do Sol existiam os súditos, os homens ultramarinos, aqueles que construíam o mundo político-econômico das conquistas e que aprenderão, com o tempo, a burlar a necessidade de viver atrás de títulos, honras e mercês da coroa portuguesa. Tempos cruéis, tempos de crises, tempos do fim da luminosidade solar em suas conquistas, e quando, as sombras antes de qualquer coisa, deviam representar os interesses regionais e locais. Experiência que Minas Gerais foi uma das primeiras a vivenciar de perto. 